\title{
Undergraduate Psychology Students' Perceptions About the Use of ICT for Health Purposes
}

\author{
Rubén Nieto $^{*}, 1$, Mercè Boixadós ${ }^{1}$, Eva Aumatell ${ }^{1}$, Anna Huguet ${ }^{2}$ and Eulàlia Hernández ${ }^{1}$ \\ ${ }^{I}$ PSiNET research group, Internet Interdisciplinary Institute, Universitat Oberta de Catalunya, Spain \\ ${ }^{2}$ IWK Health Centre, Halifax, Canada
}

\begin{abstract}
Objective: Information and communication technologies (ICT) have great potential for health care. In this study we explore undergraduate psychology students' perceptions about different specific uses of ICT for health (i.e. online interventions, health information websites, telehealth and online social networks).
\end{abstract}

A total of 113 students answered an online survey designed to gather their perceptions about the use of these four types of interventions for health purposes.

Results: Results showed that online interventions and telehealth were assessed as the best ways of using ICT for health, while the worst way was using social networks for health. The most frequently mentioned advantages were related to the fact that ICT can help with access to information and/or treatments, and that they are comfortable. The most frequently mentioned disadvantages were related to the quality of the information (for social networks and health information websites) and the fact that they were considered impersonal (for telehealth and online interventions).

Conclusions: Students were not very enthusiastic about the use of ICT for health. Education is needed to change these perceptions and increase the likelihood that they will incorporate ICT in their future practice.

Keywords: Anova, health, information and communication technologies, perceptions, psychology students, telehealth.

\section{INTRODUCTION}

Information and communication technologies (ICT) represent a revolution for health that can be used in many different ways. For example, they have been used extensively (and their use is growing) to create online interventions that have proved to be effective for different health problems [1-3]. These interventions usually encompass different materials (written and multimedia) aimed to provide education and teach skills to improve coping with health conditions. Some of these interventions include support from others (including health professionals or coaches), whereas others are totally self-directed.

Furthermore, ICT allow patients the possibility of making contact with professionals in real time from a distance to manage a health issue through what is known as telehealth. The possibilities here are enormous, depending on the technology that can be employed, the purpose of the contact, and the health issue $[4,5]$.

Beyond telehealth, ICT can also be used to provide health information. In fact, the number of people searching for information on the Internet is increasing over time, and health professionals have been obliged to use the internet to

*Address correspondence to this author at the PSiNET research group, Internet Interdisciplinary Institute, Universitat Oberta de Catalunya, Spain; Tel: +34-933263538; Fax: +34-933568822; E-mail: rnietol@uoc.edu better inform citizens about health issues. Health information on the Internet can promote a change in the patient's role, as patients can become more active and access information that is relevant to their condition $[3,6]$.

Online social networks are another way to use ICT for health purposes. Their use has pervasively penetrated in our everyday lives, which means they have great potential for health care. These tools make it possible to create groups to share knowledge and resources among peers interested in a specific health topic (see, for example, the work by Farmer et al., [7] for a recent search of groups for health in facebook). Although few studies are available, interest in these groups and in the use of social networks for health is also increasing in the scientific literature, as they have proven to have some effects on health, social support and empowerment [8-10].

In general terms, among the main advantages of using ICT for health, the following can be highlighted [11, 12]: easier access to professionals with specific training in a specific disorder; convenience for patients (they can follow interventions when and where it is convenient for them); better management of professionals' time (they can use ICTbased interventions, saving "face-to-face time" for those who require a more intensive intervention or have complicated problems); reduction in health disparities (evidence-based treatments can be widely disseminated); reduction in the 
stigma associated with some treatments; increase in user and supplier control of the intervention; decrease in health care costs (although more research is needed [13]).

Therefore, it seems clear that ICT are useful for health, and their use is increasing. If psychologists used and/or enhanced the use of ICT for health purposes, everyone could obtain significant benefits. However, during their undergraduate education, psychologists often do not receive specific training about how ICT can play a role in providing health care services. In fact, most of the curricula for the bachelor's degree in psychology, at least in Spain, do not include specific training in the use of ICT for health.

An important point would be to assess psychology students' perceptions about the use of ICT for health. As students have not received specific training and do not have extensive knowledge about this field, examining their views would allow us to explore their original perceptions and their willingness to gain knowledge about this area, drawing future lines of education for them. This issue is important, since with adequate knowledge students can be a key element in creating a real challenge in favor of using ICT for practicing health psychology.

Our goal is to evaluate what undergraduate psychology students think about different specific uses of ICT for health (i.e. online interventions, health information websites, telehealth and online social networks). For this purpose,we have created an online survey and preliminarily applied it to a group of students from the Universitat Oberta the Catalunya.

\section{MATERIALS AND METHODOLOGY}

\section{Participants}

Data for the study were collected from May to June 2011. Students in the Psychology Degree Program at the Universitat Oberta de Catalunya (UOC) were invited to participate.

\section{Procedure}

The UOC is an online university whose mission is to provide people with lifelong learning and education opportunities. All the academic activity is performed online.

Students were invited to participate through different messages sent into different spaces of the UOC virtual campus. These spaces include informal virtual spaces (e.g. the space of the psychology group where a lot of psychology students work together to organize activities and share knowledge) and formal virtual spaces (e.g. all the virtual classrooms of subjects coordinated by the first author of this work). In the message inviting them to participate, we briefly introduced the study's purpose. If students were interested, they were asked to agree online to participate and complete the online survey, which took about 20 minutes.

\section{Measures}

An ad-hoc online survey with 46 items was created to gather psychology students' perceptions about the use of ICT for health, since, to our knowledge, no standard survey exists.
With this survey we wanted to gather their opinions about four different ways ICTs can be used for health: online interventions, telehealth, health information websites and social networks. We chose to include online interventions, health information websites and telehealth because they have received considerable attention in the scientific literature, as the introduction describes. Moreover, we included social networks because, although they have not received much attention in the scientific literature, they have strong potential as they are widely used by the population.

In the survey, for each type of intervention, we first provided a brief introduction explaining to what we were referring. After this, we asked students to what extent they thought each form of intervention could: 1) improve the way of taking care of health; 2) improve their health; 3) substitute face-to-face health services; and 4) be used as a complement to other face-to-face health services. They were asked to rate each of these 4 outcomes on a $0-10$ scale (0-Not at all, 10extremely). We also asked them to report up to 5 advantages and disadvantages of each form of intervention, using open questions. Questions gathering socio-demographic information and asking about the use of the Internet in their daily lives were also included for descriptive purposes.

The online survey was implemented using Limesurvey (http://www.limesurvey.org/).

\section{Data Analyses}

All the analyses were performed using the SSS 20.0 statistical package. Descriptive statistics were computed for the socio-demographic data and the use of ICT. Descriptive statistics and ANOVAs of repeated measures were computed for the four different ways of using ICT for health explored in this study. We checked the assumptions of sphericity (Mauchly test) and applied the necessary corrections in the absence of homogeneity (i.e. Lower-Bound estimate). With these analyses, we wanted to explore the general perception of the usefulness of each form of intervention, considering and comparing the perceived utility of the 4 different types of intervention.

A qualitative analysis of the contents was performed to analyze advantages and disadvantages of each form of intervention. Two authors (EA and $\mathrm{MB}$ ) independently reviewed the narrative responses and agreed on categories within each question. Any differences were discussed until agreement was reached. Cohen's kappa coefficient was between $80 \%$ and $86 \%$ for all the categorizations performed.

\section{RESULTS}

\section{Participants' Sociodemographic Characteristics and the Use of ICT in Daily Life}

A total of 128 students accessed the online survey. Of them, the data from 113 have been included in the analyses: 101 completed the entire survey; 9 additional students only completed information about two of the four ways of using ICT for health that we asked about (health information websites and online interventions); 3 students only completed information about three of the fours ways of using ICT that we asked about (health information websites, online 
treatments and telehealth). 15 students did not provide any information or they only provided sociodemographic data and were not included in any of the analyses. Unfortunately, we do not have information about how many students received the enrollment message. Therefore, we cannot estimate the response rate.

Mean age for the sample was 24.31 years (SD: 9.44; range: 18-68). Most of them were female $(82.3 \%)$ and worked at a paid job in addition to studying $(84.1 \%)$. Most of them had been studying psychology for one year or less $(43.3 \%)$. The rest had been studying psychology for the following periods: $13.3 \%$ between 2 and 3 years; $24.8 \%$ between 4 and 6 years; $18.6 \%$ for more than six years.

Table 1 displays descriptive data for the use of the Internet. As the table shows, the participants accessed the Internet quite often, basically from their home or workplace,

Table 1. Use of ICT Descriptive Statistics.

\begin{tabular}{|c|c|}
\hline $\begin{array}{r}\text { Frequency of connection to internet } \\
\text { At least once a day } \\
\text { At least once a week }\end{array}$ & $\begin{array}{c}99.1 \% \\
0.9 \%\end{array}$ \\
\hline \multicolumn{2}{|l|}{ Places from where they connect to internet } \\
\hline Home ( $\%$ yes) & $99.1 \%$ \\
\hline Workplace ( $\%$ yes) & $43.4 \%$ \\
\hline Place of study ( $\%$ yes) & $9.7 \%$ \\
\hline Point from the Administration ( $\%$ yes) & $0.9 \%$ \\
\hline Other ( $\%$ yes) & $0.9 \%$ \\
\hline \multicolumn{2}{|l|}{ Devices used to connect to internet } \\
\hline Desktop computer & $56.6 \%$ \\
\hline Laptop & $80.5 \%$ \\
\hline Mobile phone & $24.8 \%$ \\
\hline Tablet & $4.4 \%$ \\
\hline \multicolumn{2}{|l|}{ Hours per week of connection to internet for personal } \\
\hline purposes & $54.9 \%$ \\
\hline 0 - 10 hours & $27.4 \%$ \\
\hline $11-20$ hours & $10.6 \%$ \\
\hline $21-30$ hours & $2.7 \%$ \\
\hline $31-40$ hours & $2.7 \%$ \\
\hline $41-50$ hours & \\
\hline \multicolumn{2}{|l|}{ Hours per week of connection to internet for } \\
\hline $0-10$ hours & $31 \%$ \\
\hline $11-20$ hours & $21.2 \%$ \\
\hline $21-30$ hours & $18.6 \%$ \\
\hline $31-40$ hours & $8 \%$ \\
\hline $41-50$ hours & $8 \%$ \\
\hline More than 50 hours & \\
\hline
\end{tabular}

and using a desktop computer or a laptop. Most of them used the Internet for personal purposes no more than 10 hours per week, and between 11 and 20 hours per week for academic or professional purposes.

At the time of the survey, $97.3 \%$ had searched for health information on the Internet, $10.9 \%$ had used social networks for health purposes, $8.7 \%$ had used telehealth, and $2.6 \%$ had followed an online intervention for health purposes.

\section{Assessment of Four Different Ways of Using ICT for Health}

As Table 2 shows, in general terms, online interventions and telehealth were the best assessed ways of using ICT for health, whereas the worst was using social networks for health. Below, we give detailed information about each outcome assessed.

On improving how to take care of health, online interventions received the highest ratings (mean of 5.3, in an scale of 0 to 10), followed by health information websites, telehealth and social networks. ANOVA results showed that there were significant differences among the means for the four forms of intervention $(F=19.74 ; d f: 3 ; p<.001)$. An examination of paired contrasts (see Table 2) showed that these significant differences were due to the fact that social networks were considered significantly worse than the other three intervention options for improving how to take care of health. Please, see Table $\mathbf{2}$ for complete descriptive information and ANOVA results for this outcome and the other three outcomes assessed.

For improving health, the best rated form of intervention was again online interventions, followed by telehealth, health information websites and social networks (the latter received a 1.5 mean score of usefulness that was very low compared to the others). The ANOVA results showed that there were significant differences in the mean values of the four types of interventions $(F=65.29 ; d f: 1 ; p<.001)$. Paired comparisons showed that social networks were rated significantly worse than the other three forms of interventions for improving health. Moreover, online interventions were rated significantly higher than looking for information.

As for being a substitution for a professional opinion, telehealth was the best option, followed by online interventions, social networks and health information websites. In all cases, the mean scores were under 4 , and especially low for health information websites. The ANOVA results showed that there were significant differences among the four means $(F=19.71 ; d f: 1 ; p<.001)$. Paired comparisons showed that health information websites were rated significantly worse than the other three types of interventions, and that both online interventions and telehealth were considered better than social networks.

Finally, when students were asked to rate the four ways of using ICT as a complement, the highest ratings were for online interventions, followed by telehealth, health information websites and social networks. In this case, the ANOVA also showed significant differences $(F=31.17 ; d f$ : $1 ; p<.001)$. Paired tests suggested that social networks were again considered significantly worse as a complement than the other three ways of using ICT. Online interventions and telehealth were considered equally, and online interventions 
Table 2. Assessment of four different types of intervention.

\begin{tabular}{|c|c|c|c|c|c|}
\hline & $\begin{array}{c}\text { Health information } \\
\text { websites (1) }\end{array}$ & Online Intervention (2) & Telehealth(3) & Social Network (4) & $\begin{array}{l}\text { Pair, Comparisons } \\
\text { (IC } 95 \% \text { of dif) }\end{array}$ \\
\hline \multirow{6}{*}{$\begin{array}{l}\text { Improve how you } \\
\text { take care of your } \\
\text { health }\end{array}$} & \multirow{6}{*}{$5.13(2.27)$} & \multirow{6}{*}{$5.27(2.57)$} & \multirow{6}{*}{$4.73(2.66)$} & \multirow{6}{*}{$3.30(2.59)$} & $1=2(-0.85 \div 0.57)$ \\
\hline & & & & & $1=3(-0.5 \div 1.29)$ \\
\hline & & & & & $1>4 *(0.99 \div 2.67)$ \\
\hline & & & & & $2=3(-0.21 \div 1.28)$ \\
\hline & & & & & $2>4 *(1.24-2.7)$ \\
\hline & & & & & $3>4 *(0.74 \div 2.13)$ \\
\hline \multirow{6}{*}{ Improve your health } & \multirow{6}{*}{$4.06(2.32)$} & \multirow{6}{*}{$5.06(2.58)$} & \multirow{6}{*}{$4.93(2.49)$} & \multirow{6}{*}{$1.5(2.10)$} & $\left.1<2^{* *}(-1.77 \div-0.23)\right)$ \\
\hline & & & & & $1=3(-1.76 \div 0.14)$ \\
\hline & & & & & $1>4 *(1.88 \div 3.25)$ \\
\hline & & & & & $2=3(-0.67 \div 0.93)$ \\
\hline & & & & & $2>4 *(2.86 \div 4.27)$ \\
\hline & & & & & $3>4 *(2.61 \div 4.26)$ \\
\hline \multirow{6}{*}{$\begin{array}{l}\text { Can substitute } \\
\text { professional's opinion }\end{array}$} & \multirow{6}{*}{$1.73(2.02)$} & \multirow{6}{*}{$3.61(2.64)$} & \multirow{6}{*}{$3.75(2.80)$} & \multirow{6}{*}{$2.67(2.65)$} & $1<2 *(-2.68 \div-1.08)$ \\
\hline & & & & & $1<3^{*}(-2.83-\div-1.21)$ \\
\hline & & & & & $1<4 * *(-1.64 \div-0.24)$ \\
\hline & & & & & $2=3(-0.9 \div 0.63)$ \\
\hline & & & & & $2>4 * * *(0.07 \div 1.81)$ \\
\hline & & & & & $3>4 * *(0.21 \div 1.95)$ \\
\hline \multirow{6}{*}{$\begin{array}{l}\text { It is a good } \\
\text { complement to the } \\
\text { professional's opinion }\end{array}$} & \multirow{6}{*}{$4.70(2.81)$} & \multirow{6}{*}{$5.83(3.11)$} & \multirow{6}{*}{$5.51(2.89)$} & \multirow{6}{*}{$3.11(3.03)$} & $1<2 *(-1.93 \div-0.33)$ \\
\hline & & & & & $1=3(-1.74 \div 0.12)$ \\
\hline & & & & & $1>4 *(0.68 \div 2.51)$ \\
\hline & & & & & $2=3(-0.42 \div 1.05)$ \\
\hline & & & & & $2>4 *(1.92 \div 3.52)$ \\
\hline & & & & & $3>4 *(1.62 \div 3.19)$ \\
\hline
\end{tabular}

$* \mathrm{p}<.001 ; * * \mathrm{p}<.01 ; * * * \mathrm{p}<.05$

were considered significantly better than health information websites.

\section{Main Advantages and Disadvantages of the Four Different Types of Intervention}

A total of 6 categories of advantages and 6 for disadvantages were isolated from the students' responses (the same categories were used for the four different forms of intervention). Please, see Table $\mathbf{3}$ for a description of these categories and examples or quotes.

Tables $\mathbf{4}$ and $\mathbf{5}$ summarize the percentages of responses for each category. Percentages in each category were calculated on the basis of the total responses for each question. Characteristics with a percentage above $10 \%$ are highlighted in bold.

Regarding the advantages (Please, see Table 4) of health information websites, the most important advantage was the "Access/Support" category. The next most frequently-cited advantage category was "Immediacy". Finally, the
"Comfortable/Time saving" category received a percentage of responses of $11.8 \%$. For online interventions, "Comfortable/Time saving" and "Access/Support" were also among the most frequently cited categories. The third most frequent response was the category "Privacy/anonymity" (15.3\%). For telehealth, the three main categories of advantages were the same as those suggested for health information websites, but in a different order, considering the percentage of responses: "Comfortable/Time saving" (33.1 \% ), "Immediacy" (28.1 $\%)$, "Access/Support" (22.3\%). Additionally, the category "Privacy/Anonymity" obtained a frequency of $12.9 \%$ for this form of intervention. Finally, for social networks, the most frequent advantage was Access/Support (79.7 \%), followed by the "Wide-ranging" category (10.2\%). In relation to the advantages it is worth noting that the category "Cost saving" was also highlighted, but its frequency was not superior to $10 \%$ for any of the four types of interventions. 
Table 3. Categories of advantages and disadvantages.

\begin{tabular}{|c|c|c|}
\hline \multicolumn{3}{|c|}{ ADVANTAGES } \\
\hline Category & Brief definition & Examples of quotes \\
\hline Access/Support & $\begin{array}{l}\text { Facilitates access to knowledge, and/or access to help or } \\
\text { support. }\end{array}$ & $\begin{array}{l}\text { "Facilitate the access to a professional" } \\
\text { "Feeling of support in case of emergency or need" } \\
\text { "Contact with other people with similar problems" }\end{array}$ \\
\hline $\begin{array}{l}\text { Comfortable/Time } \\
\text { saving }\end{array}$ & $\begin{array}{l}\text { Comfortable for using it from home, at the most } \\
\text { convenient time, and easily. It also makes it possible to } \\
\text { optimize personal time. }\end{array}$ & $\begin{array}{l}\text { "It's easy to access the information" } \\
\text { "It is not necessary to move" }\end{array}$ \\
\hline Immediacy & $\begin{array}{l}\text { Immediate access and obtaining what you need } \\
\text { immediately. }\end{array}$ & $\begin{array}{l}\text { "You can find a response quickly" } \\
\text { "Obtaining feedback about questions-responses immediately" } \\
\text { "Quick solution to problems" }\end{array}$ \\
\hline Wide-ranging & Multiple sources and options are available. & $\begin{array}{l}\text { "Diversity of opinions" } \\
\text { "Different treatment options" } \\
\text { "Diversity" }\end{array}$ \\
\hline Cost savings & Makes it possible to reduce costs. & $\begin{array}{l}\text { "It can be cheaper than a face-to-face treatment" } \\
\text { "The cost is lower" }\end{array}$ \\
\hline Privacy / Anonymity & $\begin{array}{l}\text { They respect users' anonymity, intimacy and/or } \\
\text { confidentiality. }\end{array}$ & $\begin{array}{l}\text { "Confidentiality" } \\
\text { "They can be helpful for people with shyness or social problems who } \\
\text { do not feel comfortable being in front of a professional, because they } \\
\text { maintain their identity" }\end{array}$ \\
\hline \multicolumn{3}{|c|}{ DISADVANTAGES } \\
\hline Category & Brief definition & Examples of quotes \\
\hline $\begin{array}{l}\text { Negative psychological } \\
\text { perception }\end{array}$ & $\begin{array}{l}\text { The use of a particular ICT resource can lead to negative } \\
\text { thoughts, beliefs, emotions and/or perceptions as a } \\
\text { consequence of the resource's characteristics or } \\
\text { contents. }\end{array}$ & $\begin{array}{l}\text { "Written information can be misinterpreted". } \\
\text { "To create false expectations or erroneous ideas in relation to a specific } \\
\text { health topic" }\end{array}$ \\
\hline $\begin{array}{l}\text { Negative self- } \\
\text { management }\end{array}$ & $\begin{array}{l}\text { ICT can lead to self-diagnosis, self-treatment, self- } \\
\text { assessment of the heath situation and/or negative beliefs } \\
\text { or decisions in relation to health management. }\end{array}$ & $\begin{array}{l}\text { "To adopt the belief that with this intervention you will never need the } \\
\text { physician's intervention" } \\
\text { "People daring to self-medicate based on what they have read on the } \\
\text { Internet" }\end{array}$ \\
\hline Quality & $\begin{array}{l}\text { Aspects related to the reliability, credibility, rigor, } \\
\text { control of the resource and/or professionals. }\end{array}$ & $\begin{array}{l}\text { "The difficulty of knowing whether the person attending to you is a } \\
\text { qualified professional" } \\
\text { "The main problem is related to the truthfulness of the information" }\end{array}$ \\
\hline Impersonal & $\begin{array}{l}\text { The lack of human contact and the loss of details related } \\
\text { to the human interaction. }\end{array}$ & $\begin{array}{l}\text { "Depersonalization" } \\
\text { "Losing face-to-face information" }\end{array}$ \\
\hline Difficulty in selecting & $\begin{array}{l}\text { Difficulty in selecting adequate information and/or } \\
\text { resources among the multiple sources available. }\end{array}$ & $\begin{array}{l}\text { "To select valid information" } \\
\text { "Difficulties related to choosing relevant information" }\end{array}$ \\
\hline Technology & $\begin{array}{l}\text { It is necessary to have technological devices to access } \\
\text { the information and resources, to know how to use these } \\
\text { devices, and/or knowing that you are exposed to dangers } \\
\text { related to their use. }\end{array}$ & $\begin{array}{l}\text { "Previous knowledge } \\
\text { about ICT use is needed" } \\
\text { "Internet can fail, you can be hacked, ..." }\end{array}$ \\
\hline
\end{tabular}

Regarding the main disadvantages, for health information websites and social networks, the most frequently reported category was "Quality" (see Table 5). This was followed by the categories "Negative psychological perception" and "Negative self-management". Additionally, for health information websites, the "Difficulty in selecting" category also had a percentage of responses higher than $10 \%$.For online interventions and telehealth, the most frequent category was "Impersonal", followed by "Quality". Additionally, for telehealth, the categories "Negative psychological perception" and "Technology" also received percentages of responses that were higher than $10 \%$. 
Table 4. Advantages.

\begin{tabular}{|c|c|c|c|c|}
\hline Advantages & $\begin{array}{l}\text { Health information } \\
\text { websites }(\mathrm{N}=\mathbf{2 4 6})^{*}\end{array}$ & $\begin{array}{l}\text { Online interventions } \\
\qquad(\mathbf{N}=\mathbf{1 7 7})^{*}\end{array}$ & $\begin{array}{l}\text { Telehealth } \\
(\mathrm{N}=139)^{*}\end{array}$ & $\begin{array}{l}\text { Social networks } \\
\qquad(\mathrm{N}=118)^{*}\end{array}$ \\
\hline Access/Support & $61.0 \%$ & $23.2 \%$ & $22.3 \%$ & $79.7 \%$ \\
\hline Comfortable /Time saving & $11.8 \%$ & $41.8 \%$ & $33.1 \%$ & $0.8 \%$ \\
\hline Immediacy & $13.4 \%$ & $9.6 \%$ & $28.1 \%$ & $3.4 \%$ \\
\hline Wide-ranging & $7.3 \%$ & $0.6 \%$ & $0 \%$ & $10.2 \%$ \\
\hline Cost savings & $1.2 \%$ & $1.7 \%$ & $0.7 \%$ & $0 \%$ \\
\hline Privacy / Anonymity & $2.8 \%$ & $15.3 \%$ & $12.9 \%$ & $1.7 \%$ \\
\hline Others & $2.4 \%$ & $7.9 \%$ & $2.9 \%$ & $4.2 \%$ \\
\hline
\end{tabular}

*N refers to number of responses.

Table 5. Disadvantages.

\begin{tabular}{|c|c|c|c|c|}
\hline Disadvantages & $\begin{array}{l}\text { Health information } \\
\text { websites } \\
(\mathbf{N}=\mathbf{2 3 5})^{*}\end{array}$ & $\begin{array}{l}\text { Online interventions for } \\
\text { health problems } \\
(\mathbf{N}=\mathbf{1 7 2})^{*}\end{array}$ & $\begin{array}{l}\text { Telehealth } \\
(\mathbf{N}=110)^{*}\end{array}$ & $\begin{array}{l}\text { Social networks } \\
\qquad(\mathrm{N}=123)^{*}\end{array}$ \\
\hline Impersonal & $1.7 \%$ & $42.4 \%$ & $30.0 \%$ & $3.3 \%$ \\
\hline Negative psychological perception & $21.7 \%$ & $7.0 \%$ & $10.0 \%$ & $20.3 \%$ \\
\hline Technology & $0.4 \%$ & $5.2 \%$ & $13.6 \%$ & $3.3 \%$ \\
\hline Difficulty in selecting & $10.2 \%$ & $0 \%$ & $0 \%$ & $6.5 \%$ \\
\hline Others & $6.4 \%$ & $16.3 \%$ & $21.8 \%$ & $9.8 \%$ \\
\hline
\end{tabular}

*N refers to number of responses.

\section{DISCUSSION}

Students perceived some usefulness of the four ways of using ICT for health explored in this study, but they were not very enthusiastic. Specifically, our results showed that online interventions and telehealth were the best rated types of interventions overall: they received a mean score of around 5 out of 10 for all the outcomes, except for being a substitute for professionals' opinions (the mean was about four for both forms of intervention). Both types of interventions were significantly better than social networks on the four outcomes. Moreover, online interventions were significantly superior to health information websites for all the outcomes, except improving how to take care of health; and telehealth was significantly superior to health information websites on being a substitute for professionals' opinions.

We expected to find a better assessment, especially for online interventions and telehealth, because both of these types of interventions have received strong support in the literature, as mentioned in the introduction [1-3]. In contrast, the ratings for health information websites can be considered more congruent with the available literature; many studies analyzing the quality of websites with information dedicated to specific health issues have shown that the quality of the available information is not always adequate (see, for example, the following recent studies: [14-17]). Social networks received the worse rating, which is congruent with the scientific scenario and its development because, as stated in the introduction, the literature available about the use of social networks for health is scarce.

The advantages suggested by the students in general were basically related to the fact that ICT can help with access to information and/or treatments, and that they are comfortable. These results are congruent with the advantages suggested in the literature for using ICT for health $[11,12]$. Regarding the disadvantages, the students suggested that the most important problem with health information websites and social networks was the quality of the information. This finding is not surprising because, as mentioned above, the quality of health information available on the internet is not always adequate. Along these lines, some studies have pointed out that patients need criteria that can help them to use and evaluate internet health information $[1,18$; among others].

For telehealth and online interventions, the most frequent disadvantage was related to the fact that they were perceived as impersonal. 
Finally, the results of this study can be considered preliminary. If we want to promote the use of ICT by future psychologists, we need to move forward and explore the perceptions of other groups of students in order to gain further knowledge about the situation and design effective training strategies. Basically, we think this study should be extended to psychology students from other universities because the sample for this study consisted of students at a university that uses ICT as a basis for learning. These students may be more in favor of using ICT for health than others who study in traditional universities with face-to-face teaching, as they are more used to using ICT for learning.

Although more research is needed, this preliminary study shows that psychology students are not very enthusiastic about the uses of ICT for health. We can, therefore, state that they need more training in this field in order to change their attitudes and foment the use of ICT (considering its proven advantages in the available literature) in their future professional practice.

\section{CONFLICT OF INTEREST}

The authors confirm that this article content has no conflicts of interest.

\section{ACKNOWLEDGEMENTS}

This work has been supported by the PSiNET research group, which is supported by the Catalan Government (SGR09-197). We are also grateful to the students who completed the survey for this study.

\section{REFERENCES}

[1] Cuijpers P, Straten A, Andersson G. Internet-administered cognitive behavior therapy for health problems: a systematic review. J Behav Med 2007; 31: 169-77.

[2] Portnoy DB, Scott-Sheldon LAJ, Johnson BT, Carey MP. Computer-delivered interventions for health promotion and behavioral risk reduction: a meta-analysis of 75 randomized controlled trials, 1988-2007. Prev Med 2008; 47: 3-16.
[3] Ybarra ML, Eaton WW. Internet-based mental health interventions. Ment Health Serv Res 2005; 7: 75-87.

[4] McGeary DD, McGeary CA, Gatchel RJ. A comprehensive review of telehealth for pain management: where we are and the way ahead. Pain Pract 2012; 12: 570-7.

[5] Polisena J, Tran K, Cimon K, Hutton B, McGill S, Palmer K. Home telehealth for diabetes management: a systematic review and meta-analysis. Diabetes Obes Metab 2009; 11: 913-30.

[6] Hernández E, Armayones M, Guillamón N, Nieto R. Salud a través de la Red: una paradoja en la sociedad del conocimiento [Health trough the Net: a paradox in the knowledge society]. Revista de Psicoterapia 2009; 19: 7-32.

[7] Farmer AD, Bruckner Holt CEM, Cook MJ, Hearing SD. Social networking sites: a novel portal for communication. Postgrad Med J 2009; 85: 455-9.

[8] Ahmed OH, Sullivan SJ, Schneiders AG, McCrory P. i Support: do social networking sites have a role to play in concussion awareness? Disabil Rehabil 2010; 32: 1877-83.

[9] Bender JL, Jimenez-Marroquin M-C, Jadad AR. Seeking support on facebook: a content analysis of breast cancer groups. JMIR 2011; 13: e16.

[10] De la Torre-Díez I, Díaz-Pernas FJ, Antón-Rodríguez M. A content analysis of chronic diseases social groups on facebook and twitter. Telemed J E Health. agosto de 2012; 18(6): 404-8.

[11] Griffiths F, Lindenmeyer A, Powell J, Lowe P, Thorogood M. Why are health care interventions delivered over the internet? a systematic review of the published literature. JMIR 2006; 8: e10.

[12] Ritterband LM, Tate DF. The science of internet interventions. Introduction. Ann Behav Med 2009; 38: 1-3.

[13] Tate DF, Finkelstein EA, Khavjou O, Gustafson A. Cost effectiveness of internet interventions: review and recommendations. Ann Behav Med 2009; 38: 40-5.

[14] Del Giglio A, Abdala B, Ogawa C, et al. Quality of internet information available to patients on websites in Portuguese. Rev Assoc Med Bras 2012; 58: 645-9.

[15] Dillon WA, Prorok JC, Seitz DP. Content and quality of information provided on canadian dementia websites. Can Geriatr J 2013; 16: 6-15

[16] Fast AM, Deibert CM, Hruby GW, Glassberg KI. Evaluating the quality of Internet health resources in pediatric urology. J Pediatr Urol 2013; 9: 151-6.

[17] Showghi NN, Williams AC de C. Information about male chronic pelvic and urogenital pain on the internet: an evaluation of internet resources. Pain Med 2012; 13: 1275-83.

[18] Eysenbach G, Köhler C. Health-related searches on the Internet. JAMA 2004; 291: 2946.

\footnotetext{
Received: September 20, 2014

Revised: November 25, 2014

Accepted: November 25, 2014

(C) Nieto et al.; Licensee Bentham Open.

This is an open access article licensed under the terms of the Creative Commons Attribution Non-Commercial License (http://creativecommons.org/licenses/by-nc/3.0/) which permits unrestricted, non-commercial use, distribution and reproduction in any medium, provided the work is properly cited.
} 